\title{
JOHN DEWEY E A APRENDIZAGEM COMO EXPERIENCIA
}

\author{
JOHN DEWEY AND THE LEARNING FROM EXPERIENCE \\ JOHN DEWEY Y EL APRENDIZAJE COMO EXPERIENCIA
}

Fernando Mariano Placides ${ }^{1}$

Jose Wilson da Costa ${ }^{2}$

1 Doutorando em Educação pela PUC Minas. Mestre em Filosofia pela UFMG Graduado em Filosofia pela PUC Minas - Professor do Departamento de Filosofia PUC Minas. Lattes: http://lattes.cnpq.br/9241123306607594 - ORCID: 0000-0001-98494800 e-mail: fplacides@gmail.com

2 Doutor em Ciências da Informação pela UFMG. Professor do PPGE da PUC Minas. Mestre em Eng. Elétrica pela UFMG. Graduado em Eng. Elétrica pela UFMG. Lattes: http://lattes.cnpq.br/4411956765694711 ORCID: 0000-0002-6210-701X e-mail: jwcosta01@gmail.com 


\section{RESUMO}

É inegável o impacto da teoria de John Dewey na educação. Suas ideias questionaram concepções pedagógicas tradicionais e se colocaram contra séculos de um processo educacional no qual o conhecimento era centrado em conteúdos transmitidos de forma pronta e fechada. Dewey apontou para a necessidade de que o processo ensino-aprendizagem centralize-se nas experiências vivenciadas e na ressignificação dessas experiências em um modo semelhante a um fazer artístico. Ele também advogou a importância do estímulo ao protagonismo do estudante e de sua capacidade de questionar e reconstruir o conhecimento. O presente artigo analisa o pensamento educacional de John Dewey com foco em alguns dos principais conceitos de sua teoria como o princípio de continuidade, o conceito de experiência, a ideia de atividade e o que o autor chama de reconstrução do conhecimento.

\section{PALAVRAS-CHAVE}

John Dewey; Educação; Aprendizagem; Arte; Experiência.

\section{ABSTRACT}

The impact of John Dewey's theory on education is undeniable. His ideas questioned traditional pedagogical concepts and stood against centuries of an educational process in which knowledge was centered on content transmitted in a ready and closed manner. Dewey pointed to the need for the teaching-learning process to be centered on the experiences lived and on the re-signification of these experiences in a way similar to an artistic practice. He also advocated the importance of encouraging the student's role and his ability to question and reconstruct knowledge. This article analyzes the educational thought of John Dewey focusing on some of the main concepts of his theory such as the continuity principle, the experience concept, the idea of activity and his concept of reconstruction.

\section{KEY WORDS}

John Dewey; Education; Learning; Art; Experience.

\section{RESUMEN}

El impacto de la teoría de John Dewey en la educación es innegable. Sus ideas cuestionaban las concepciones pedagógicas tradicionales y se enfrentaban a siglos de un proceso educativo en el que el conocimiento se centraba en contenidos transmitidos de forma dispuesta y cerrada. Dewey señaló la necesidad de que el proceso de enseñanza-aprendizaje se centre en las experiencias vividas y en la resignificación de estas experiencias de manera similar a una práctica artística. También defendió la importancia de fomentar el protagonismo de los estudiantes y su capacidad para cuestionar y reconstruir conocimientos. Este artículo analiza el pensamiento educativo de John Dewey centrándose en algunos de los principales conceptos de su teoría como el principio de continuidad, el concepto de experiencia, la idea de actividad y lo que el autor denomina reconstrucción del conocimiento.

\section{PALABRAS CLAVE}

John Dewey; Educación; Aprendizaje; Arte; Experiencia. 
Certa vez, em 1902, John Dewey percorreu as lojas de material escolar de Chicago procurando por carteiras escolares novas e mais adaptadas à proposta pedagógica que desejava implementar em sua Laboratory School, uma escola de ensino básico por ele criada. Na ocasião, ouviu de um vendedor a seguinte resposta: "Receio não ter o que vocês desejam. Vocês querem carteiras onde as crianças possam trabalhar; todas essas que tenho são apenas para ouvir?". A surpreendente fala do vendedor carregava consigo o peso de toda uma tradição pedagógica que relegava o estudante a mero espectador do processo educacional, a ouvinte e não a agente ativo de seu aprendizado. Essa, aliás, é a tecla na qual a teoria de Dewey bate insistentemente: só é possível o verdadeiro aprendizado através da ação ativa e participativa do estudante, ou seja, learning by doing.

Não obstante todas as transformações no processo ensino-aprendizagem que foram influenciadas pelo pensamento deweyano e de tantos outros autores que apontaram na mesma direção de atenção e reconhecimento da importância do estudante no processo educativo, ainda temos muito a avançar. Continuamos precisando de novas carteiras nas quais os estudantes possam "trabalhar" e não apenas "escutar" e os ensinamentos de Dewey fornecem elementos preciosos para construção de uma prática pedagógica mais ativa e efetiva. É nesse sentido, que o presente artigo propõe a discussão das principais ideias de John Dewey no campo educacional procurando extrair ensinamentos que possam subsidiar e melhorar a prática pedagógica contemporânea.

John Dewey (1859-1952) é um pensador que se filia ao pensamento filosófico do pragmatismo. Ele, juntamente com Charles Sanders Peirce (1839-1914) e William James (1842-1910), são considerados os fundadores dessa corrente filosófica surgida nos Estados Unidos no final do século XIX. Peirce foi o primeiro a propor um novo papel para a filosofia e sua relação com a ciência. A palavra "pragmatismo" tem sua origem no termo grego pragma, que tem por significado ação, trabalho, negócio. De maneira geral, os filósofos pragmáticos defendem que a verdade de uma situação ou proposição é obtida pelo exame de sua utilidade prática, de sua aplicação. A intenção dos pragmáticos é apontar para ação, mostrando que o efeito de uma ideia se torna mais importante do que sua origem. Para esses autores, a visão tradicional e equivocada do que seja "a verdade" foi construída pensando a mente como capaz de representar o mundo como um palco interno, um lugar onde é possível criar uma ideia, uma cópia do que está lá fora e, ainda, ter acesso a um tipo de conhecimento especial ou privilegiado em relação a toda a natureza. Adotando uma postura contrária à visão tradicional, os pragmatistas propõem que o pensamento não é algo que ocorra de uma maneira isolada da natureza. Para eles, as ideias são verdadeiras na medida em que ajudam a entrar em relação satisfatória com outras partes da experiência.

Para Dewey, a noção de um pensamento dissociado da vida prática dominou a filosofia ocidental e foi sustentada pela teoria da lógica. A tradição filosófica, segundo ele, se esforçou em demonstrar logicamente a verdade revestindo de lógica aquilo que não possui racionalidade intrínseca. Araújo (2008), deixa isso muito claro ao afirmar que: 
Como não era possível apontar para o fato (por não ser possível verificação empírica naquela época) era preciso convencer da veracidade de crenças não mais aceitas exclusivamente pela autoridade social ou pelo hábito. Daí empregar-se a lógica, a demonstração, o rigor da definição. $O$ aspecto que a tantos afasta da filosofia é o que constitui uma das principais razões para aqueles que se dedicam a ela. (ARAÚJO, 2008, p. 3)

Para Dewey, o pensamento não pode ser visto como um aglomerado de impressões sensoriais, nem como responsável por criar algo chamado "consciência" ou como a manifestação de algo especial e absoluto. O pensamento deve ser visto como algo que executa uma função mediadora e instrumental e que evoluiu para servir aos interesses da sobrevivência e do bem-estar da humanidade.

Provém da visão de que as teorias são instrumentos de ação a opção de Dewey em nomear sua proposta filosófica pelo termo "instrumentalismo" em vez de "pragmatismo". Ele afirma que "o conhecimento acontece quando tem-se a percepção das conexões de um objeto e de sua aplicabilidade em uma dada situação" (DEWEY,1959).

Ao propor a adoção de um método pragmático para a análise do conhecimento, Dewey deseja substituir conceitos tradicionalmente usados como, por exemplo, "estabilidade" e "essência" por termos como "evolução" e "mudança". Para ele, a "natureza é conduzida pelos projetos humanos porque não é mais escrava de propósitos metafísicos ou teológicos" (DEWEY, 1948, p. 41). E o progresso da ciência acontece porque ela se volta para o mundo da matéria e supera obstáculos e dificuldades sempre olhando para esse mundo natural. Do mesmo modo, a educação e a moral só poderão progredir se seguirem por essa mesma trilha.

A interação entre o "organismo" e as "coisas que o rodeiam" é a origem do pensamento. O pensar surge da perplexidade, da confusão ou dúvida e é preciso alguma coisa particular que o ocasione ou provoque (DEWEY, 1943, p. 40). Partindo de sua epistemologia, ou seja, a teoria de como o conhecimento acontece, Dewey constrói sua filosofia da educação, que será o corolário de todo seu pensamento filosófico.

A filosofia da educação deweyana ergue-se sobre o tripé: experiência, investigação e descoberta. Anísio Teixeira (SUCUPIRA, 2015, p. 23), afirmou em artigo de 1955 que "Só uma lógica da experiência, uma lógica da investigação e da descoberta, como é a de Dewey, pode ajudar a vencer as falsas divisões, dualismos e conflitos que vêm criando e nutrindo a injustificada Babel moderna."

Para compreendermos a teoria da educação deweyana é preciso olhar mais de perto alguns dos principais conceitos de seu pensamento, forjados pelo autor durante o percurso de sua trajetória intelectual.

Uma das características do pensamento deweyano é a organicidade, ou seja, suas propostas vão sendo construídas em um entrelaçamento de conceitos que se relacionam e explicam mutuamente. Assim, mesmo que sigamos a proposta de uma análise mais específica de alguns de seus conceitos, precisamos ter em mente que 
eles se relacionam e formam uma teoria orgânica e coerente.

\section{O princípio de Continuidade}

Dewey constrói uma filosofia de caráter naturalista e evolucionista. Como afirma Broens (2009), no ano de 1909, no qual se comemorava cinquenta anos da publicação de "Origem das Espécies", Dewey escreve seu artigo "A influência do darwinismo na Filosofia". Nesse artigo, o autor ressalta que poucos modificaram de forma tão profunda o conceito de ciência quanto Charles Darwin e suas teorias da evolução. Ao dizer isso, Dewey também está se referindo ao percurso de seu próprio pensamento filosófico. As ideias de Darwin exerceram tanta influência na filosofia de Dewey que Carvalho; Silva e Cunha (2014, pág. 143), chegam a afirmar que a metáfora fundamental do pensamento deweyano é construída sobre as bases evolucionistas darwinistas ${ }^{1}$.

É de uma perspectiva evolucionista que Dewey pensa o conceito de continuidade. Para ele, a tradição filosófica, na tentativa de explicar a origem e estrutura do conhecimento, criou falsos antagonismos, divisões ou antíteses que poderiam ser sintetizadas como um tipo de pensamento dualista. Esses dualismos filosóficos, como, por exemplo, as separações entre mente e mundo, natureza e experiência ou entre razão e experiência surgiram como frutos de uma estrutura social também dualista. Como afirma o filósofo,

encontramos a origem destas divisões nas sólidas e altas muralhas que extremam os grupos sociais e as classes dentro de um grupo, como as distinções entre ricos e pobres, homens e mulheres, pessoas nobres e de baixa condição, e entre os que mandam e os que são mandados. (DEWEY, 1979, pág. 366)

Foi no cenário de uma sociedade de estamentos que uma filosofia dual germinou e tornou-se dominante, produzindo doutrinas contrárias sobre os processos cognitivos. Isso ocorreu, por exemplo, com as escolas do Empirismo e do Racionalismo, que são contundentemente criticadas por Dewey (1979). Ele aponta que o engano comum de ambas as escolas foi deixar de perceber que, tanto a função do estímulo sensorial ou da experiência para o empirismo, quanto a função da reflexão ou da razão para o racionalismo, são funções que se relacionam e estão ligadas à reorganização da experiência em um processo de continuidade ou de coerência da natureza e da vida. Por isso,

A "razão" é precisamente a aptidão de fazer a matéria da experiência

\footnotetext{
1 CARVALHO; SILVA e CUNHA, (2014) apontam como metáfora fundamental do pensamento de Dewey a ideia de "percurso indeterminado". "O discurso de Dewey é vinculado à metáfora 'percurso indeterminado', pois situa a evolução como processo destituído de finalidades previamente inscritas em um plano pré-determinado, estando sujeito somente às relações que se estabelecem, de maneira imprevisível, entre os organismos e as condições ambientais que os circundam." (CARVALHO 2014 pág. 143)
} 
anterior levar a perceber a significação da matéria de uma nova experiência. Uma pessoa é racional no grau em que habitualmente tem clarividência para ver um evento, que imediatamente lhe incide nos sentidos, não como uma coisa isolada, mas em conexão com a experiência comum da humanidade. (DEWEY, 1979, pág. 377)

Para ilustrar o que entende por processo contínuo, Dewey (1979) usa a metáfora de um carpinteiro aplainando a madeira e recebendo impressões contínuas de seus órgãos sensoriais. Essas respostas motoras engendram o próximo estímulo sensorial, significando que, na ação do carpinteiro, razão e experiência são parte de um mesmo processo cognitivo.

Em outro momento, para mostrar a relação estreita entre sentidos e razão, ele usará o exemplo de uma criança que, ao empinar uma pipa, recebe impressões em suas mãos da tensão da corda e, ao mesmo tempo tem os olhos na pipa que está no céu, e ainda opera todos os processos para mantê-la no ar. $\bigcirc$ ato da criança deve ser visto como um coisa só. Sentidos e pensamentos juntos e direcionados para uma ação, um objetivo a ser realizado. Assim, ele aponta para a noção de unidade na natureza e para a importância de se perceber o processo cognitivo como um todo e guiado por uma finalidade.

Os seres humanos não estão à parte, contemplando a natureza. Pelo contrário, eles são também natureza e sua mente é fruto dos processos evolutivos ocorridos ao longo do tempo. É nesse contexto a afirmação deweyana de que

\begin{abstract}
A experiência contém em si princípios de conexão e de organização [...] Mesmo nos níveis ínfimos de vida, torna-se indispensável algum grau de organização. A própria ameba necessita alguma continuidade em sua atividade, e alguma adaptação ao meio ambiente. Sua vida e experiência não podem consistir em sensações atomizadas momentâneas, autoenclausuradas. Sua atividade está em referência com o ambiente e com o que já aconteceu ou está para acontecer. Esta organização, intrínseca à vida, torna desnecessária uma síntese sobrenatural e sobre-empírica, ao mesmo tempo em que ministra a base e o material para o desenvolvimento da inteligência como fator organizador da experiência. (DEWEY, 2011, p.94)
\end{abstract}

Nessa perspectiva, poderíamos afirmar que o ser humano não é tão diferente de uma ameba. Apenas faz o que ela faz em um nível maior de organização. Embora esse pensamento darwinista possa ferir nosso complexo de Narciso, ele nos levará a uma compreensão da totalidade do processo cognitivo. Segundo Amaral (1990, pág. 51), a distinção que realmente importa, que tem significado na visão de Dewey, não ocorre mais entre o "mundo" e "aqueles que conhecem o mundo". Tal distinção deverá ser entre as diferentes maneiras de ser dentro do movimento das coisas, ou seja, entre um modo físico e um modo inteligentemente definido, que é a forma de relação inteligente que a criatura viva tem com a natureza. Por essa razão é que se pode dizer que Dewey naturaliza o ser humano, mostrando que aquilo que a espécie faz, do ponto de vista cognitivo, é apenas mais um elemento dentre os outros do mundo. 
Dewey relata a existência de um fluxo contínuo, um processo natural que alcança na cognição sua mais sofisticada faceta. Tal cognição, que pode ter como exemplo o método científico, surge da relação prática do homem na natureza e é fruto da busca para solução de problemas. Ele dirá que o método experimental é novo como recurso científico, como meio sistematizado de adquirir conhecimentos, mas é velho como a vida, em seu caráter de artificio prático (DEWEY, 1979, pág. 372).

É nessa relação de continuidade entre experiência, pensamento e vida, tomados aqui como uma coisa só, que os seres humanos aprendem. É a partir da busca das soluções de problemas, dos mais simples aos mais complexos, que se produz o conhecimento. $O$ ato de conhecer, para o pragmatista Dewey, tem um sentido prático, aplicável às experiências presentes e futuras.

Em suma, a função do conhecimento é tornar uma experiência livremente aproveitável em outras experiências. [...] Por outras palavras, o conhecimento é uma percepção das conexões de um objeto, que o torna aplicável em dada situação. (DEWEY, 1979, pág. 373)

Em tal ótica, a relação pedagógica deve se dar como uma atividade de pesquisa. De tal sorte que, semelhante a um cientista que procura a solução de um problema e daí constrói suas proposições e teorias, o estudante deverá ser estimulado a perceber a relação de continuidade entre o que aprende e o que vive.

Dewey (1979) criticará as escolas que se empenham mais em formar discípulos do que em formar pesquisadores. Tal postura nos processos educacionais tem origem exatamente na visão de que a educação é uma preparação para a vida e não a vida em si mesma. Assim, o que por vezes faz a escola, é colocar em seu currículo uma lista infindável de conteúdos que se justificam apenas com vistas a sua importância futura.

Dewey alerta que, ao agirem assim, elas

consideram o conhecimento como coisa completa em si mesma, independentemente de sua utilização, para tratarmos daquilo que ainda vai ser. E é esta omissão que as vicia e as faz adotar métodos educacionais condenados por uma adequada concepção do conhecimento. (DEWEY, 1979, pág. 376)

Por adequada concepção do conhecimento deve-se entender exatamente tudo o que foi descrito como a proposta de abandono dos dualismos e a adoção de uma visão integrada de todo o processo cognitivo. Por fim, o conselho do autor sobre a adoção da continuidade como princípio na educação é de que

Deve haver continuidade entre o aprendizado escolar e o extraescolar. Deve existir livre interação entre os aprendizados. Isto só é possível quando existem numerosos pontos de contato entre os interesses sociais de um e de outro. Poder-se-ia conceber a escola como um lugar em que houvesse espírito de associação e de atividade compartida, sem que, entretanto, sua vida social representasse ou copiasse, quer o mundo existente além das paredes da escola, quer a vida de um mosteiro. (DEWEY, 1979, pág. 394) 


\section{O conceito de experiência}

O conceito de experiência é um dos mais centrais no pensamento de Dewey. Ele dá tanta importância a esse tema que trata dele em vários de seus escritos durante sua carreira filosófica, chegando a afirmar que alguns gramas de experiência valem muito mais que uma tonelada de teorias².

Em sua obra "Democracia e Educação", quando fala da experiência, ele a associa ao conceito de pensamento nomeando o capítulo com o título "Experiência e Pensamento". Por óbvio, em sua visão, existe ligação íntima entre experimentar e pensar. Segundo ele, não se experimenta primeiro para depois pensar. As duas coisas acontecem simultaneamente, num processo único, de continuidade. Quando experimentamos, já estamos pensando.

Na perspectiva deweyana, o ato de experimentar está relacionado com a ideia de interação. Com um processo de troca e transformação que acontece quando o sujeito é exposto ao objeto de conhecimento. Tal exposição ao objeto do conhecer é a própria natureza se conhecendo. Seria como se a natureza estivesse interagindo consigo mesma, pois os seres humanos são também parte inerente, inseparável dela. Dewey não vê uma divisão ontológica entre o mundo e o sujeito. Para ele, o sujeito também é o mundo e aprende, ou forma hábitos no processo contínuo de interação. Por isso, dirá que

A experiência, em suma, não é uma combinação do espírito com o mundo, do sujeito com o objeto, do método com a matéria, e sim uma única interação contínua de grande diversidade de energias" (literalmente inumeráveis). (DEWEY ,1979, pag. 184)

Ele descreverá o processo da experiência como tendo dois elementos. Um ativo e outro passivo. O caráter ativo da experiência parte do sujeito e é constituído pela ação, pela tentativa e atividade que se faz em direção à coisa experimentada. Esse modo ativo, constitui-se em todo movimento que fazemos em direção ao mundo, ao objeto de pesquisa, e se dá quando apontamos a mente e os sentidos para algo. Por outro lado, o caráter passivo da experiência é o que "se sofre" da ação, o que recebemos como consequência. Assim,

Quando experimentamos alguma coisa, agimos sobre ela, fazemos alguma coisa com ela; em seguida sofremos ou sentimos as consequências. Fazemos alguma coisa ao objeto da experiência, e em seguida ele nos faz em troca alguma coisa: essa é a combinação específica, de que falamos. (DEWEY, 1979, pág. 152).

\footnotetext{
2 A frase de Dewey é "uma onça de experiência vale mais que uma tonelada de teorias simplesmente porque é só pela experiência que qualquer teoria tem importância vital e verificável. Uma experiência, uma humílima experiência, é capaz de originar ou de conduzir qualquer quantidade de teoria (ou conteúdo intelectual), mas uma teoria, à parte da experiência, não pode nem mesmo ser definidamente apreendida como teoria. (DEWEY, 1979, pág. 158)
} 
É somente nesse processo de ir e vir, de interação com o objeto de estudo que acontecerá a experiência e, consequentemente, o aprendizado. Experimentar envolve atividade e passividade. Segundo o autor,

\begin{abstract}
Aprender da experiência é fazer uma associação retrospectiva e prospectiva entre aquilo que fazemos às coisas e aquilo quê em consequência essas coisas nos fazem gozar ou sofrer. Em tais condições a ação torna-se uma tentativa; experimenta-se o mundo para se saber como ele é; o que se sofrer em consequência torna-se instrução - isto é, a descoberta das relações entre as coisas. (DEWEY, 1979, pág. 153)
\end{abstract}

Ao deixarmos de ver o conhecimento como uma categoria separada do mundo, passamos a dar relevância para a cooperação entre o organismo e o meio, surgida dos processos transacionais que acontecem entre eles. Nas palavras de Araújo (2008, pág. 4), "não será possível separar o ar dos pulmões, o conhecido do conhecedor, os dados sensíveis da experiência em foco". Em "Experiência e Natureza" (1958), Dewey, deixa bem claro essa ideia ao afirmar que

o organismo atua sobre as coisas que o rodeiam; valendo-se de sua própria estrutura, simples ou complexa. Em sua consequência, as mudanças que produzem nesse meio circundante reagem por sua vez sobre o organismo e sobre suas atividades. O ser vivente sofre as consequências de seu próprio agir. Essa íntima conexão entre o agir e sofrer ou padecer é o que chamamos experiência. O agir ou sofrer, desconectados um do outro não constitui nenhum dos dois a experiência. (DEWEY, 1958, p. 110)

É neste sentido que a simples apreensão de informações ou o contato com coisas práticas, não se constitui em uma experiência. Se o sujeito se relaciona com o objeto em uma via de mão única, na qual apenas se aproxima de um conteúdo mas tal conteúdo não provoca o retorno da reflexão, o refluxo, teremos uma experiência pobre, incompleta ou, até mesmo, experiência nenhuma, pois, a simples atividade não constitui-se uma experiência.

É assim que se poderia falar em um aprendizado mecanizado, que, na concepção deweyana, seria aquele que não engaja corpo e mente, mas enfatiza apenas um desses aspectos, deixando de lado o processo dinâmico de ambos e reforçando essa falsa dicotomia. Sobre isso, Dewey (1979, pág. 156) dirá que "é mecânico todo o processo de ensino que restringe a atividade corpórea ao ponto de chegar-se à separação do corpo e do espírito - isto é, da percepção do sentido do que se está fazendo."

A experiência é fundamental. Não uma experiência de cunho positivista que afasta sujeito e objeto. Para Dewey, compreender o processo biológico da construção do conhecimento não é sinônimo de pensar na possibilidade de uma psicologia da mente que seja capaz de revelar os segredos da alma ou de uma realidade intrínseca e única do sujeito. O modelo biológico que o autor construirá descarta a ideia de sujeito pensante de um lado e de uma natureza a ser representada do outro. $\bigcirc$ que se propõe é a noção de continuidade, já aqui descrita, que nega a ruptura entre experiência e natureza. 
Não há um sujeito interno e separado do mundo. A experiência envolve ação, pensamento e reflexão e, principalmente, um sujeito ativo. Uma experiência terá valor e será uma boa experiência na medida em que produza no sujeito percepções continuadas do mundo. Que se prolongue, mesmo depois da ação, promovendo a reflexão e, ocasionalmente, até a mudança.

Dewey também ressalta uma outra dimensão muito rica da experiência que é sua capacidade de requisitar não só a mente, mas também as emoções e a sensibilidade. A interação, fruto da boa experiência, envolverá os aspectos emocionais, criativos e imaginativos ligados à arte. Essa ideia torna-se explícita em sua obra "Arte como experiência".

Segundo Westbrook (2010), a pedagogia de Dewey exige que os educadores realizem uma tarefa muito difícil, qual seja, a de reincorporar os temas de estudo na experiência, pois os temas tratados nos currículos, como todos os conhecimentos humanos, são produtos do esforço do homem para resolverem os problemas que a experiência lhes apresentou. Porém, antes que esses conhecimentos fossem construídos formalmente, eles foram abstraídos das problemáticas em que foram originalmente desenvolvidos, dos contextos práticos da vida. Sobre isso, Dewey faz o alerta:

Pois basta lembrarmo-nos daquilo que se considera, às vezes, nas escolas, como aquisição de conhecimentos, para se ter acordo de sua falta de relações frutíferas com a experiência possuída pelos estudantes - e da amplitude com que se parece acreditar que constitui conhecimento a mera apropriação da matéria armazenada em livros. Embora a matéria aprendida constituísse conhecimentos verdadeiros para aqueles que os descobriram e de cuja experiência eles faziam parte, nada há na mesma que a converta em conhecimentos para os discípulos. Se a matéria não frutificar na própria vida do indivíduo, o mesmo seria ensinarem-se coisas sobre o planeta Marte ou sobre qualquer país do mundo das fantasias. (DEWEY, 1979, pág. 376)

Embora a teoria de Dewey tenha influenciado os atuais processos educacionais, o que se percebe, muitas vezes na prática, é uma má compreensão do que seja experiência e uma adoção de metodologias que não privilegiam a interação em uma perspectiva deweyana. E os estudantes ainda são tratados como alunos. Aqui, a expressão "aluno" quer apontar para uma situação de falta de interação. O próprio autor nos lembra que a palavra aluno significa, etimologicamente, alguém que está sendo nutrido, alimentado, quase que numa atitude de passividade.

Apreender pela experiência, constitui-se em um dos pilares fundamentais da teoria de Dewey. A verdadeira experiência educativa e significativa só ocorrerá no ambiente de experimentação. Essa é a forma como aprendemos na vida, como resolvemos os problemas que se nos apresentam. Acumular experiências, ressignificálas e aplicar as soluções aprendidas em novos contextos, é o caminho para o verdadeiro aprendizado. É nessa direção que Dewey afirma que a

A educação praticada intencionalmente (ou escolar) deveria apresentar 
um ambiente em que essa interação proporcionasse a aquisição daquelas significações que são tão importantes que se tornam por sua vez em instrumentos para a ulterior aquisição de conhecimentos. (DEWEY ,1979, pag. 301)

\section{A ideia de Interesse}

A palavra interesse sugere aquilo que está entre, (inter - esse). Aquilo que reúne duas coisas que, de outra maneira, estariam separadas. Na educação, uma das coisas que caracteriza tal distância ou espaço que separa as coisas, é o tempo.

Dewey lembra-nos que

No aprendizado, as energias ou poderes atuais do aluno são o estágio inicial; o objetivo do professor representa o limite remoto. Entre os dois ficam os meios - isto é, as condições intermediárias: atos a serem praticados; obstáculos a superar; instrumentos a usar e aplicações a fazer. Somente por meio deles, no sentido literal de tempo, as atividades iniciais chegarão a um remate satisfatório. (DEWEY, 1979, p.139)

O desafio colocado para os educadores é o de como despertar o interesse do estudante sobre os vários temas das disciplinas, sabendo que eles serão necessários e importantes no futuro, mas entendendo que eles não aparecem assim ao estudante no momento presente? Como trabalhar a energia e a capacidade inicial dos estudantes canalizando-as aos objetivos propostos?

Para responder essa pergunta precisamos trazer para a discussão o conceito de "esforço", aqui entendido como o controle de nossas ações pela vontade com o objetivo de se alcançar algum resultado. A ênfase da ideia de esforço é mais com vistas ao resultado final do que ao processo. Diante disso, outra questão emerge: qual é o equilíbrio, o meio-termo, entre o interesse e o esforço?

A ideia de continuidade será fundamental para respondermos a essas indagações. Só haverá interesse do aluno se esse perceber uma identificação entre ele e o objeto estudado. Identificação que nasce naturalmente quando o estudante se depara com temas e propostas curriculares que levam em conta a continuidade do conhecimento. Quando os problemas não são artificialmente propostos, mas sim organicamente conduzidos. Dewey dirá que "interesse significa que o eu e o mundo exterior se acham juntamente empenhados em uma situação em marcha" (DEWEY, 1959, p. 137)

Em seu artigo, "Interesse e Esforço", o autor procura se posicionar entre as duas teorias antagônicas que defendiam, ou a primazia do estímulo e do cultivo ao interesse do estudante ou a valorização e supremacia do esforço na educação. Os defensores da primeira teoria, a do interesse, propunham que, quanto mais estímulos relacionados aos seus interesses próprios os estudantes recebessem, maior seria sua atenção aos conteúdos e, por conseguinte, melhor o aprendizado. A educação, 
nessa perspectiva, deveria se preocupar em despertar o interesse dos estudantes e o prazer de aprender. Por outro lado, os defensores da segunda teoria, a do esforço, advogavam que o importante seria submeter o estudante aos processos de controle e verificação da escola, usando de todos os recursos possíveis para que eles se aplicassem aos estudos e mostrando que este esforço seria recompensado, seja em um futuro próximo já na escola, por meio de notas e outros estímulos, ou em um futuro distante, pela sociedade, com a realização profissional.

Tal problema assim colocado, ou seja, a ideia de escolha entre uma ou outra teoria, é o tipo de questão que Dewey sempre atacou, procurando promover a desconstrução de antagonismos ou dualismos. Com esse intuito, ele dirá que ambas as escolas, seja a dos defensores do interesse, seja a dos defensores do esforço, abordaram a questão de modo reducionista e, principalmente, não levaram em conta a ideia de que a educação deve ser um processo contínuo sem concentrar-se apenas no prazer momentâneo ou nas finalidades a posteriori. Mais que isso, a proposta deweyana não será uma fusão desses dois extremos, mas uma abordagem nova da questão, apontando para a dissolução dessa dicotomia e uma visão integrada do processo.

Como indica Rocha $(2011)^{3}$, Dewey irá mostrar que, tanto a teoria do interesse, quanto a teoria do esforço cometerão o mesmo erro, pois elas irão separar o "eu" e o "objeto". Por um lado, a ideia de se tornar uma coisa interessante não é verdadeira porque, para Dewey, o interesse já está dado na coisa na medida em que há continuidade. Isso quer dizer que não deveríamos criar estratégias postiças, forçando a escolha de problemas ou questões que pareçam interessantes ao estudante, mas sim, construir atividades que consigam partir dos temas reais da vida daqueles que são colocados diante de tais atividades.

Já a teoria do esforço, formará pessoas apenas acostumadas a uma recompensa, a um prêmio final, seja num futuro próximo, como as notas atribuídas por atividades, seja num futuro distante, como o sucesso, a independência financeira ou mesmo a realização na vida. Essa abordagem removerá do processo educacional a verdadeira experiência e o real aprendizado.

O pintor irá interessar-se por pincéis e por telas, dirá Dewey (1913), porque isso irá ajudá-lo a descobrir e promover sua capacidade artística. Essa é uma abordagem instrumental, ou instrumentalista do processo pedagógico. Tal qual um artista, que, absorvido em suas pesquisas, não vê o tempo passar, pois tem a mente completamente direcionada para seu objeto de conhecimento, no caso, a obra de arte que está produzindo, e, no processo da realização dessa obra, utiliza-se das telas e dos pincéis que compõem um todo orgânico com a atividade realizada. Poderíamos afirmar que

\footnotetext{
3 "Essa dissociação faz com que o tornar as coisas interessantes seja uma ideia falsa, dado que uma coisa não pode ser tornada mais interessante do que ela é de fato. Um dos problemas de se recorrer sempre ao estímulo externo é limitar a capacidade de iniciativa quando essa criança é deixada a si mesma. Isso pode criar também uma espécie de vício e dependência desse estímulo que vem de fora. Esse tipo de educação pode fazer com que a criança não desenvolva a autonomia necessária para decidir as coisas assim que solicitadas. Ela fica à mercê区 das determinações externas". (ROCHA, 2011, p. 113)
} 
em tal contexto, o artista emprega "todo seu interesse" e "todo seu esforço" naquilo que está fazendo.

Ao procurar dissolver a dicotomia interesse-esforço, Dewey mostra que, em educação, os dois são importantes na medida em que aconteçam como parte do processo. A seleção dos materiais, as atividades escolhidas e, até mesmo a forma de avaliação, precisam ser pensados como um conjunto.

Vale ressaltar que Dewey encara o processo de conhecer como uma pesquisa de um cientista que é movido por suas perguntas e problemas e, a partir deles, tem seu interesse despertado. O interesse surgirá na medida em que forem colocadas situações que não provoquem a ruptura da continuidade com a vida, e sim, pelo contrário, sigam o fluxo dessa continuidade na atividade proposta. Como lembra Rocha (2011), "o interesse legítimo, verdadeiro, positivo é aquele que possibilita o crescimento ou desenvolvimento contínuo de uma atividade." Em outras palavras, não se pode criar problemas artificiais, pois a simples apresentação de uma situação problema não é garantia de nascimento de um legítimo interesse.

Dewey não descarta o importante papel do esforço no processo educativo. Ele realça a ideia de que, se bem entendido, o processo de aprendizagem também envolve a dedicação, a concentração o foco, que serão empregados na medida em que o estudante se perceber envolvido no todo e não colocado como espectador ou mero executor de tarefas com vistas a ganhos futuros.

\section{O conceito de Atividade}

Falando de sua perspectiva unificadora e buscando sempre a superação das barreiras teóricas construídas no front das várias teorias pedagógicas, Dewey considera a atividade como parte da vida. Uma das definições da palavra "atividade" é movimento, e é nesse sentido que Dewey considera esse conceito. Para ele, os métodos de ensino e aprendizagem devem ser construídos com foco no fazer, no promover e realizar. A atividade não é vista como algo que deva ser dado e assimilado pelo estudante mas, pelo contrário, como processo que se movimenta.

Embora a tradição pedagógica geralmente separe fim, meio e atividade, colocando o "fim" ora como algo que antecede a atividade, ora como algo que está lá no fim, unicamente como uma coisa a ser alcançada, para Dewey todas essas coisas estão integradas. Dizer que o fim deve estar integrado à atividade significa pensar o processo em seu conjunto. Segundo ele, é o "fim" que dará sentido à atividade, desde que, já integrado a esta, e não como meta final a se revelar e ser alcançado apenas no desfecho do caminho. A ideia do autor é que o processo deve ter participação ativa do estudante já na previsão dos fins do que é feito. Uma série de ações justapostas, dirá ele, não podem ser consideradas como pertinentes.

Uma vez que os objetivos ou fins se relacionam sempre com a natureza dos resultados, a primeira coisa a considerar-se para se saber se há fins ou 
objetivos é a continuidade intrínseca do trabalho ou atividade em questão. Porque se se tratar de mera série de atos justapostos, dos quais uns devem ser feitos primeiros e outros depois, já não há problemas de fins. (DEWEY, 1979, p. 109)

Será o objetivo, em sua qualidade de fim previsto, que dirigirá a atividade. $O$ ponto relevante dessa questão da relação com a finalidade é que, ao se propor uma atividade ao estudante, a finalidade está apenas naquele que propõe e isso, para Dewey, não será verdadeira atividade e, muito menos, poder-se-ia falar em fins. Só há verdadeira finalidade quando o estudante, partindo da constatação de uma problema, propõe-se a trilhar um caminho que o solucione. Tal qual um cientista procurando por soluções, o estudante deverá percorrer o processo e apropriar-se das ferramentas necessárias à consecução de seu propósito.

Pensar a atividade em educação numa ótica de continuidade com a vida, significa assumir que a ações desenvolvidas precisam fazer sentido e se interconectarem. Elas não poder ser apenas uma lista de tarefas. Mais ainda, elas precisam surgir do processo de investigação e curiosidade para constituírem-se em verdadeira experiência. Ações que miram metas distantes e não se integram não serão consideradas verdadeiras atividades, segundo o pensamento deweyano. As ações, quando partem da verdadeira experiência, despertam o interesse, que, assume um aspecto emocional, e ativa também a razão, que entende os fins em suas consequências e resultados. Ambos, interesse e fim serão capazes de promover o engajamento na atividade.

Ressalta-se ainda, que, segundo Dewey, o fim não pode ser considerado meramente objetivo e, tampouco, o interesse completamente subjetivo. Ambos se fundem na mesma conduta e dão o sentido de totalidade que deve estar presente na atividade.

O remate do autor a essa questão aponta para a importância de não nos concentrarmos na criação de listas de tarefas que sejam, de modo já predeterminado, simplesmente colocadas ao estudante. Em alguma medida, o processo de aprendizagem precisa dar liberdade de escolha e criação ao sujeito, pois, do contrário não haverá uma atividade verdadeira.

Falar-se em objetivo ou fim da educação quando quase todos os atos de um discípulo são impostos pelo professor, quando a única ordem na sequência de seus atos é a proveniente das lições marcadas e das direções dadas por outrem, é absurdo (Dewey, 1959, p. 109).

\section{Reconstrução e a aprendizagem como forma de arte}

Dewey escreve, em 1925, a obra "Reconstrução em Filosofia". Nela, ele propõe novas perspectivas e soluções para os problemas filosóficos e para o papel do pensamento filosófico na sociedade. Em sua visão, o ser humano filosofa desde o 
momento em que procura resolver os problemas de sua vida. Para isso, utiliza a ferramenta do pensar e, no fluxo do processo evolucionário da vida, procura repassar isso aos seus descendentes por meio da educação. Portanto, é possível dizer que filosofar é aprender e que educar é ensinar a filosofar.

Tal processo de filosofar, que nesta perspectiva se confunde com o processo educativo deve levar o sujeito a uma reconstrução. Reconstruir não significa partir do nada, mas de algo com o qual se molda e faz o novo. Esse algo ao qual nos referimos é o próprio conhecimento, que tem sua nascente na verdadeira experiência. Para reconstruir, necessariamente não precisamos fazer de um modo diferente, mas precisamos nós mesmos façamos. Como no lembra Rocha (2011), é só quando o indivíduo se torna apto a utilizar as experiências passadas para novas experiências, é que poderemos dizer que houve aprendizagem e que a inteligência está em um processo de crescimento. Esse será a verdadeira reconstrução na perspectiva deweyana. Será a educação como um contínuo processo de reconstrução e reorganização da experiência que habilitará o estudante a melhor dirigir o curso de sua vida futura. Tudo o que se fez em educação será ineficaz como forma de aprendizado, se não houver, por parte do estudante, uma reconstrução, pois, sem isso, não existirá crescimento intelectual.

A reconstrução, do ponto de vista deweyano, reúne todos os conceitos que descrevemos até aqui. Só poderá acontecer na continuidade com a vida e em real processo de experiência do mundo. Além disso, como ato que parte da situação da vida, gerará interesse e engajamento do estudante pois é isso a que, segundo Dewey, pode-se chamar de uma verdadeira e frutífera atividade.

Nossa conclusão essencial é que vida é desenvolvimento e que o desenvolverse, o crescer é a vida. Traduzido em termos educacionais equivalentes, isto significa: $1 .^{\circ}$ ) que o processo educativo não tem outro fim além de si mesmo: ele é seu próprio fim; e que, $2^{\circ}{ }^{\circ}$ ) o processo educativo é um contínuo reorganizar, reconstruir, transformar. (DEWEY ,1979, p. 53)

Dewey apontou para a necessidade de o processo pedagógico centralizarse nas experiências vivenciadas pelo sujeito que aprende. Sujeito no qual se deve cultivar o protagonismo na construção do saber, principalmente por sua capacidade de questionar e reconstruir o conhecimento.

A educação, nessa ótica, passa a ser vista como a realização de experiências frutuosas e conectadas, capazes de construir os sentidos do mundo. Isso, porque a experiência não poderá ser vista como algo isolado e pontual, mas sim um processo ininterrupto que se chama vida. Nas palavras de Dewey, "continuidade e interação em sua ativa união uma com a outra fornecem a medida do significado e do valor educativo de uma experiência" (DEWEY, 1976, p. 38).

O sujeito aprende estabelecendo conexões, ligações entre pensamentos, sentimentos e intuições. A verdadeira experiência envolverá o indivíduo em sua totalidade. Isso quer dizer que o aprendizado se dará não apenas pelo intelecto que sistematiza e organiza. Também se aprende com o sentimento e a intuição. Não é por acaso que Dewey valoriza a arte, a criação e elaboração que são construídas 
pelo estudante, apontando que a humanidade estabeleceu sua história baseada na experiência e que tal experiência é, sobretudo, artística. Assim, todos os conhecimentos e proposições também se constituem obras de criação, ou seja, obras de arte.

Torna-se fundamental a valorização de todas as dimensões do sujeito no processo educacional. Tal como um artista, que imprime em sua obra seus recursos intelectuais, técnicos e afetivos, a experiência educacional acontece também fazendo uso das várias dimensões do ser humano. Portanto, a experiência deve ser vista em si mesma como uma forma de arte, pois envolve uma permanente criação e recriação do indivíduo, seja pela mudança na percepção de si e do mundo, seja pela estruturação e reestruturação do agir do sujeito.

Ao falarmos de educação como arte, não podemos esquecer que uma das características fundamentais de todo fazer artístico é a criatividade e Dewey dá grande destaque à ação criativa dos alunos apontando que a experiência é o meio fundamental para que ela aconteça. Experiência e criatividade irão se constituir nos pilares de todo o processo de aprendizagem.

Se pensarmos que as teorias epistemológicas e educacionais da modernidade estabeleceram claras e rígidas distinções entre natureza e experiência e entre arte e ciência, a teoria de Dewey, procurará mostrar a unidade desses conceitos. Um dos modos que ele encontrará para fazer isso será a valorização da experiência vista como ação estética. A arte não pode ser antagônica à ciência e, mais que isso, precisa ser vista como o modo de atividade que é carregado de sentidos e significados e que constrói o sujeito desde o início de sua vida escolar.

É inegável o impacto da teoria de John Dewey na educação. Suas ideias questionaram a concepção tradicional e se colocaram contra séculos de um processo educacional no qual o conhecimento era centrado em conteúdos transmitidos aos alunos de forma pronta e fechada e, estes, por sua vez, deveriam devolver o mesmo conteúdo aos educadores nas formas vigentes de verificação da aprendizagem.

É certo que os processos pedagógicos se transformaram, impulsionados sobretudo por teorias como as de Dewey e de outros pensadores da educação. Mas também é certo que ainda precisamos avançar mais, e que a compreensão e aplicação dos pressupostos deweyanos poderá contribuir de maneira ímpar para a educação. Muitas vezes, quando presenciamos estudantes silenciosamente e docilmente sentados, ouvindo as palavras de seus mestres, devemos nos indagar se já não é hora de comprarmos novas carteiras que sirvam para trabalhar e não apenas para escutar.

\section{Referências}

AMARAL, Maria Nazaré de C. Pacheco. Dewey: filosofia e experiência democrática. São Paulo: Perspectiva, 1990.

ARAÚJO, Inês Lacerda. Dewey e Rorty: um debate sobre justificação, experiência e o papel da ciência na cultura. Cognitio-Estudos: Revista Eletrônica de Filosofia. São Paulo, v. 
5, n. 1, p. 01-15, jan./jun. 2008.

CARVALHO, Daniele Cristine; SILVA, Tatiane; CUNHA, Marcus Vinicius. A metáfora fundamental do discurso de John Dewey. Educação e Cultura Contemporânea. Rio de Janeiro, v. 11, n. 25, p. 142-162. 2014

CUNHA, M. V. John Dewey: Uma Filosofia para Educadores em Sala de Aula. Petrópolis: Vozes, 1998.

DEWEY, John. Reconstruction in philosophy. New York: Dove Publications, 1948.

The School and Society. Chicago: The University of Chicago Press, 1953.

Experiência e educação. 2.ed. São Paulo: Companhia Editora Nacional, 1976.

Democracia e Educação. Trad. G. Rangel e A. Teixeira. São Paulo: Companhia

Editora Nacional, 1979.

Experiência e Natureza. Trad. M.O.R.P. Leme. São Paulo: Abril Cultural,1980.

A Arte como Experiência. Trad. M.O.R.P. Leme. São Paulo: Abril Cultural,1980a

Reconstrução em filosofia. São Paulo: Ícone, 2011.

Interest and Effort in Education. Cambridge - Massachusetts: The Riverside Press Cambridge, 1913.

ROCHA, Eliezer Pedroso da. O princípio de continuidade e a relação entre interesse e esforço em Dewey. Tese de Doutorado. Faculdade de Educação USP. São Paulo, 2011.

SUCUPIRA, Newton. John Dewey: uma filosofia da experiência. Revista Brasileira de Estudos Pedagógicos. Rio de Janeiro, v. 34, n. 80, p. 78-95, out./dez.1960.

TEIXEIRA, Anísio. Bases da teoria lógica de Dewey. Revista Brasileira de Estudos Pedagógicos. Rio de Janeiro, v.23, n.57, p.3-27. jan./mar. 1955.

WESTBROOK, Robert B.; TEIXEIRA, Anísio. John Dewey. Tradução e organização de José Eustáquio Romão e Verone Lane Rodrigues. Recife: Fundação Joaquim Nabuco/Editora Massangana, 2010 